\title{
Corrigendum
}

\section{Ezrin in primary cutaneous melanoma}

\author{
Suvi Ilmonen, Antti Vaheri, Sirpa Asko-Seljavaara and Olli Carpen
}

Modern Pathology (2005) 18, 872. doi:10.1038/modpathol.3800429

Correction to: Modern Pathology (2005) 18, 503-510, advance online publication, 8 October 2004; doi:10.1038/modpathol.3800300
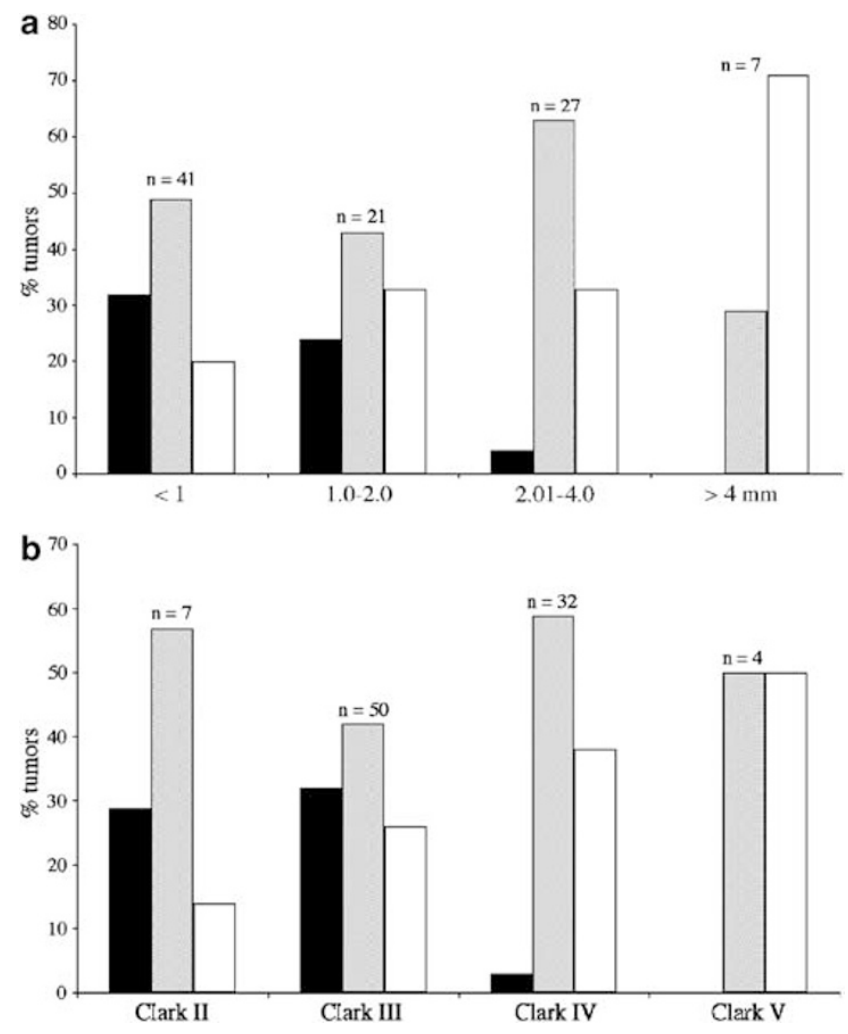

Following the publication of the above paper, the author has identified an error in part (b) of Figure 2 legend. The correct Figure 2 legend is below.
Figure 2 Correlation between ezrin immunoreactivity and melanoma thickness or invasion level. (a) Tumors were categorized according to the Breslow classification. Intensity of ezrin immunoreactivity increased with tumor thickness $(P=0.0008)$. (b) Ezrin immunoreactivity was compared with Clark classification. Increased ezrin staining was seen in higher Clark categories $(P=0.004)$. White bar $=$ immunoreactivity 2 ; gray bar $=$ immunoreactivity 1 ; black bar=immunoreactivity $0 ; n=$ number of tumors in each cateogry. 